\title{
Analysis of selected factors that generate the costs of accidents at work using the Polish construction industry as an example
}

\author{
Anna Hoła ${ }^{1}$, Bożena Hoła $^{1}$, Marek Sawicki ${ }^{1}$, Mariusz Szóstak ${ }^{1, *}$ \\ ${ }^{1}$ Wroclaw University of Science and Technology, Faculty of Civil Engineering, Poland
}

\begin{abstract}
The paper presents analysis of selected factors that generate the costs of accidents at work using the Polish construction industry as an example. The individual components of the cost of accidents have been identified. Using the statistical data published by the Central Statistical Office, the impact on the size of the cost of accidents at work of such factors as the lost time of an injured person, the lost time of other people involved in the removal of accident effects and also material losses caused by an accident, was analysed. On the basis of the conducted analysis, conclusions regarding economic losses due to accidents were formulated.
\end{abstract}

\section{Introduction}

The implementation of construction works is an activity that is burdened with a high level of risk of adverse events such as construction catastrophes, accidents at work or events that can potentially cause accidents. The construction industry is one of the most dangerous sections of the economy in most countries of the world. This is evidenced by published statistical data and reports of organizations and agencies dealing with security issues in the world such as, among others, the National Safety Council (NSC), the Bureau of Labor Statistics (BLS), the National Institute of Occupational Safety and Health Administration (OSHA), the Central Statistical Office of the European Union (EUROSTAT) and the Central Statistical Office (GUS) in Poland.

It can be concluded from statistical data published by EUROSTAT that in 2012 the construction industry was classified in second place in terms of the severity rate of accidents at work which cause more than 3 days of absence from work, and also in second place in terms of fatal accidents at work [1,2]. According to statistical data published by the Central Statistical Office (GUS), 6264 accidents happened in the construction industry in Poland in 2014, including 55 fatal accidents and 74 serious accidents [3]. In the ranking of individual sections of the economy in terms of the incidence rate of accidents, the construction industry was in a very high eighth place. The results of research published in many publications indicate that the scale of the problem related to accidents at work in the construction industry is significant.

*Corresponding author: mariusz.szostak@pwr.edu.pl 
An accident at work, in addition to human losses, also carries tangible economic losses $[1,3,4]$ related to, among others: the treatment and rehabilitation of an injured person, the suspension of production, the need to replace an injured employee with another employee, the obligation of paying compensation to an injured person, the repair or replacement of damaged equipment and sometimes the rebuilding of an entire destroyed job post.

The article attempts to analyse the accident phenomenon with regards to selected factors that generate costs. Based on the subject literature, the identification and classification of individual cost components have been made. Using statistical data published by the Central Statistical Office (GUS), analysis of selected factors that generate costs was carried out. The conducted analysis is of an estimated nature because a significant part of the costs related to an accident is difficult to calculate and not recorded.

\section{Identification of costs associated with an accident at work}

In the subject literature, the costs that generate accidents at work are often presented as a "drifting iceberg". Its visible part, located above the surface of the water, symbolizes the costs that are possible to be estimated. The much larger and invisible part of the iceberg is under the surface of the water and symbolizes the costs that are difficult to estimate and often go unnoticed. [5] The estimation of the costs of accidents at work is the subject of scientific research conducted around the world. The basis for this estimation is the identification of cost components.

Thus, the authors of the study [6] divide the costs of accidents into three groups: direct costs, indirect costs and quality of life costs. Direct costs include payments for hospitals, physicians, allied health services, rehabilitation, nursing home care, home health care, mental health payments for treatment, police, fire and emergency transport. Indirect costs include victim productivity losses, which include wage losses and household production losses, and also administrative costs, which include the cost of administering worker compensation wage replacement programs and sick leave. Quality of life costs refer to the value attributed to the pain and suffering that victims and their families experience as a result of an injury.

In turn, the authors of studies $[7,8]$ divide costs of accidents at work into two categories, namely: primer costs and secondary costs. The primer costs include the loss of productive employment as a result of premature death or injury measured in terms of time loss or wage loss. Secondary costs include employer financed fringe benefits, household production losses and payments for medical services.

In Poland, according to [3.9], there are three categories of costs of accidents at work: the costs incurred by an enterprise (CE), the costs incurred by a victim and family (CVF) and the costs incurred by the whole society (CIS). It can be expressed by the following formula:

$$
C A W=C E+C V F+C I S
$$

The costs incurred by an enterprise are the difference between the sum of the individual components of costs and compensation (C) received from insurance companies $[3,9]$ and are expressed in formula (2). The designations used in the formulas (1 and 2) are described in Figure 1.

$$
C E=(C L T+C M C a T+C O+C S+C D P+C M L+C R+C O R+O C)-C
$$




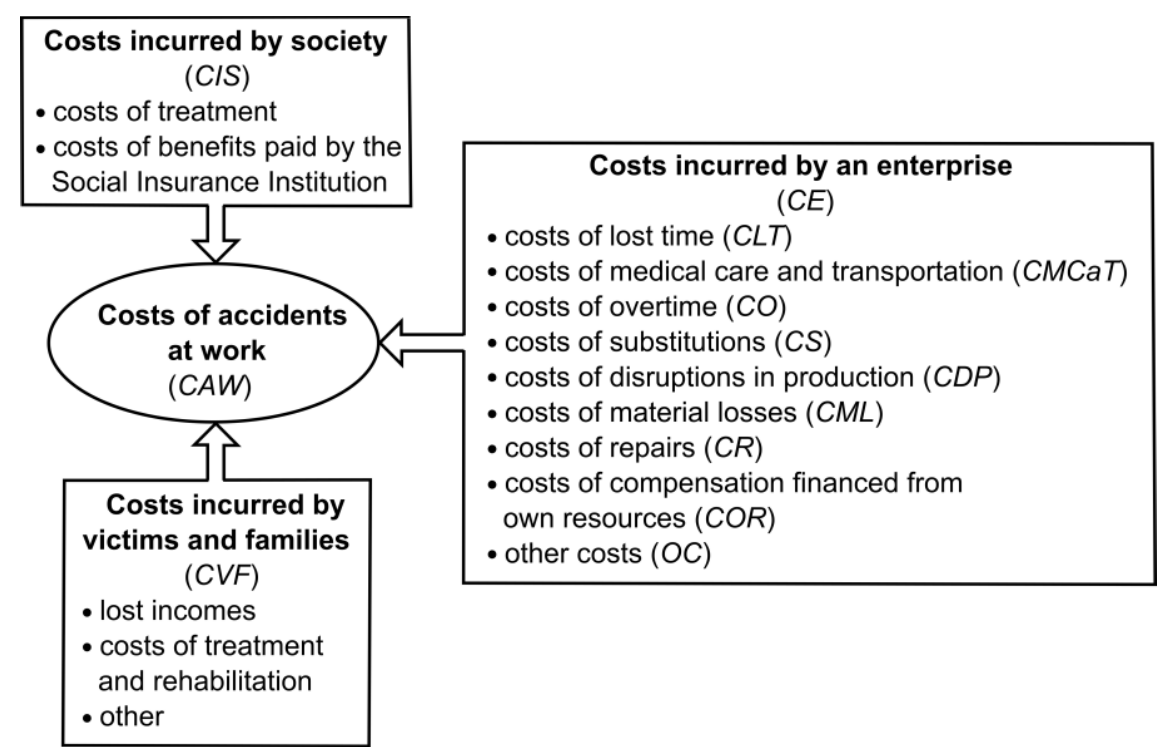

Fig. 1. Classification of costs of accidents at work

It should be noted that an accident at work causes a break in work, not only for the victim but also for other people. This break generates the so called costs of lost time (CLT), which include: the time lost by an injured person on the day of an accident and during the days of absence; working time of people organizing first aid, conducting the first aid and those reorganizing the work; time required to carry out an accident investigation and also the time necessary for planning preventive actions.

Ensuring production continuity requires the involvement of additional people on both the day of an accident and also during the days of the injured employee's absence (CO, CS). Production interruptions cause malfunctions of machines and whole production lines and the fact that they are not in use generates costs due to production losses (CDP).

An accident at work generates costs associated with providing medical help (CMCaT). This can be: transport of an injured person to a doctor or other place of medical care, the cost of bandages and medicines taken from the enterprise's infirmary or the point of medical care on a building site and also the cost of medical staff employed in the enterprise's infirmary.

Losses of property (CML) are often related to accidents at work. They include the value of damaged raw materials; semi-finished products; finished products; the lost value of machinery, equipment and vehicles; as well as the cost of buying new machines, equipment and vehicles, or the cost of their repairs (CR).

An employer often also bears the costs of financial compensations (COR), which are vested on the basis of the Labour Law by a court on the basis of a civil action. Concerning legal cases, the costs of court expert opinions and court expenses must also be taken into account.

Other costs (OC) relate to, e.g. rescue actions and penalties incurred by an enterprise due to a failure to comply with a signed agreement or contract as a result of an occurred accident. Immeasurable costs caused by the loss of image of a company in which accidents happen frequently cannot be omitted. 


\section{Factors that generate costs of accidents}

On the basis of available statistical data published by the Central Statistical Office (GUS) the following factors were analysed:

- lost time resulting from the treatment and rehabilitation of people injured in heavy and light accidents at work in the construction industry in 2014,

- the course of the accident severity rate in the time period covering the years from 1992 to 2014 and time resulting from substitutions at work,

- the cost of property losses caused by an accident at work.

\subsection{Lost time}

The consequence of accidents at work, beyond the effects causing fatal or serious injuries of the body, is the absence of employees due to their treatment and rehabilitation. Statistical data published by the Central Statistical Office indicates that the absence of employees caused by accidents at work in the construction industry is very large. Figure 2 shows the distribution of the number of people injured in accidents at work in the construction industry in 2014 in relation to the number of sick leave days [10]. This figure shows that in the construction industry accidents with a negligible degree of severity that are not eligible for sick leave also occur. However, a significant amount of accidents, represented by $54.6 \%$ of all accidents, are eligible for sick leave that lasts for more than one month.

The total number of sick leave days per total number of accidents that occurred in 2014 in the construction industry amounted to 325,364 days [5]. Assuming that the average number of working days in a month is equal to 22 , it can be calculated that 1232 employees from the construction industry were on sick leaves that lasted for a year.

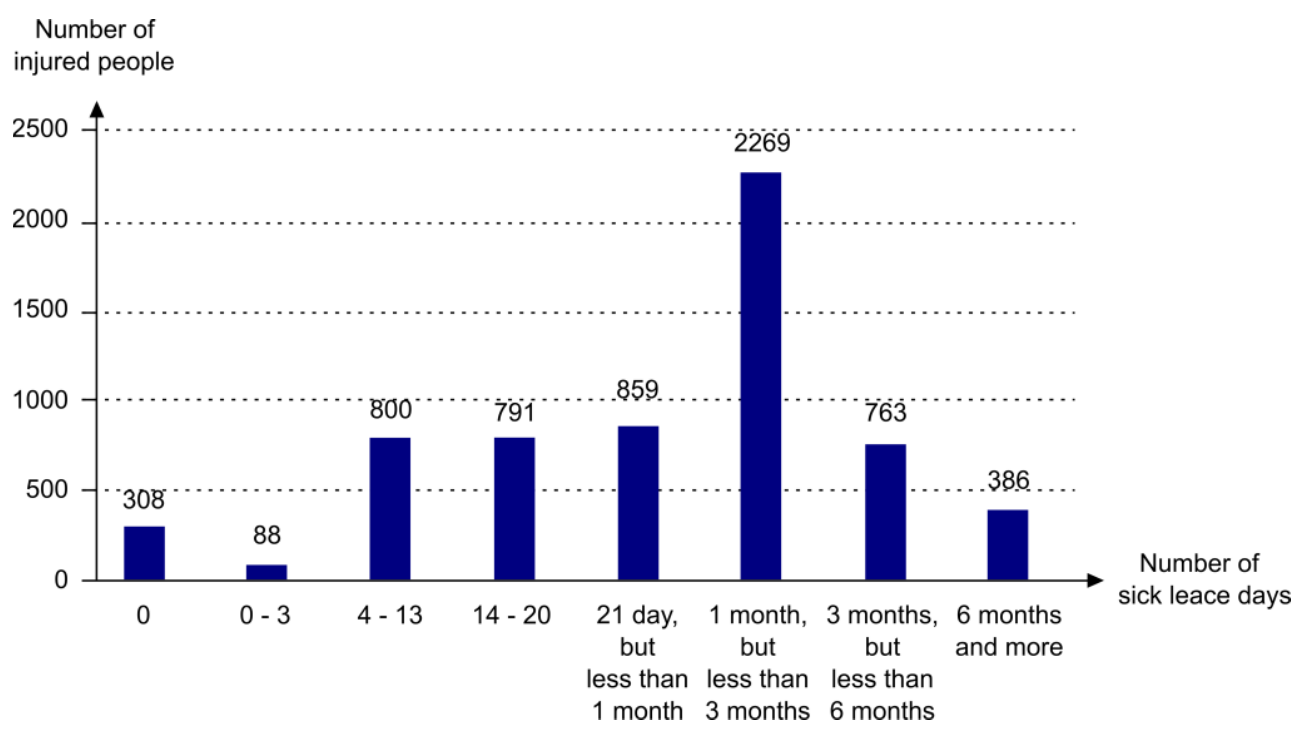

Fig. 2. Distribution of the number of people injured in accidents at work in the construction industry in 2014 in relation to the number of sick leave days. 


\subsection{The severity of accidents at work}

The phenomenon of absence from work caused by accidents is described by the severity rate of accidents, which indicates the average number of workdays lost due to sickness per one person injured in heavy and light accidents [10]. The course of changes in the value of this rate during the period between 1992 and 2014 is shown in Figure 3. After a period of dynamic growth the rate in 2006 reached a value of 56.9 days per one accident. From 2007 the severity rate had lower values and in 2014 it was equal to 52.4 workdays per injured person. The value of this rate confirms that injuries caused by accidents in the construction industry are serious and require long treatment that generates high costs. In terms of the value of this rate, the construction industry placed second in the ranking of all sections of the economy, just after mining and extraction for which the severity rate of accidents was equal to 76.8 .

The severity rate

of accidents

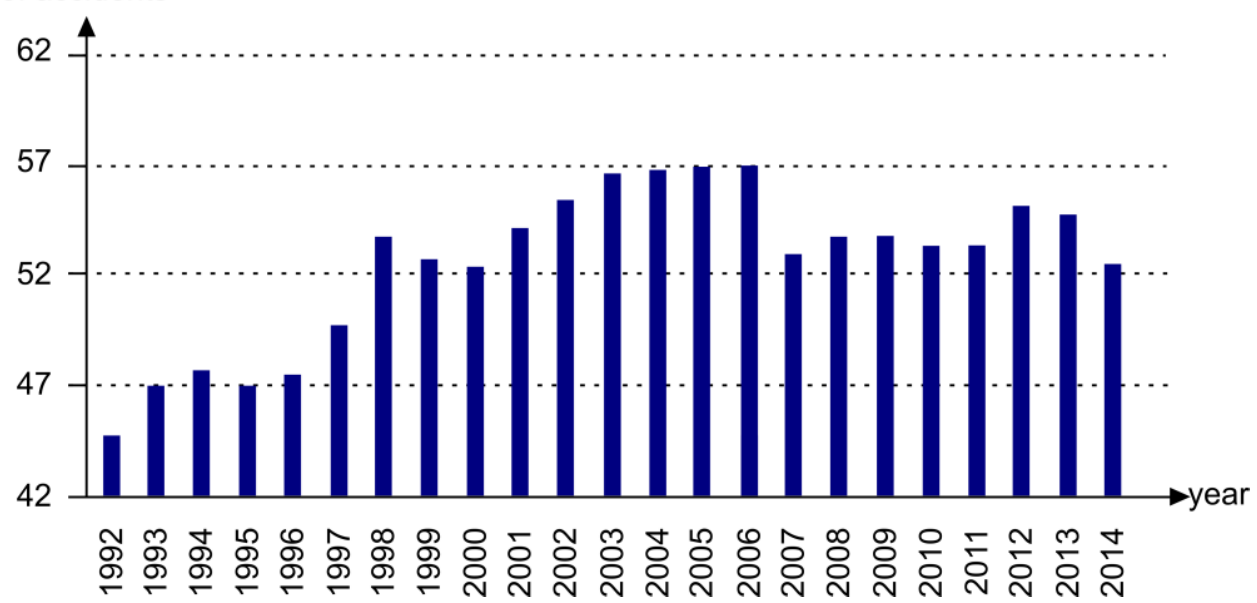

Fig. 3. The course of changes of the severity rate of accidents at work in the construction industry.

\subsection{Time losses of other people caused by accidents at work}

Removing the effects of accidents often requires the involvement of additional people, which generates additional costs. When calculating the costs of an accident it is necessary to consider the working time of employees providing first aid, the working time of workers defining the causes and circumstances of an accident at work, and in the case of the suspension of the working process, also the working time of people covered by downtime. Employee absence due to treatment and rehabilitation is often associated with the need of replacing such a person, and therefore with the employment of another person or by paying overtime to people already employed.

In 2014 in the construction industry, additional working time of such people amounted to 8437 working hours. [10]. When converting this into an 8 -hour working day, it results in about 48 working months. This means that four employees from the construction industry throughout the whole year of 2014 were involved in removing the effects of various accidents at work. 


\subsection{Material losses}

As a result of an accident at work, construction equipment, raw materials and finished goods are often destroyed. According to [10], the estimated material losses caused by accidents at work in 2014 in the construction industry, which include the total value of damaged machinery, equipment, tools, raw materials, finished products and buildings with their contents, amounted to PLN 1813.2 thousands. This represented $4.2 \%$ of the costs of material losses incurred in all sectors of the national economy, which amounted to PLN 42780 thousands. In the ranking of all sections, the construction industry was in 5th place. The greatest material losses due to accidents at work were reported in the following sections: transportation and warehousing and also manufacturing, which amounted to PLN 15179.9 thousands and PLN 14859 thousands respectively.

\section{The estimated total costs of accidents at work}

Cost analysis of 330 accidents at work that happened in different sections of the Polish economy [11] showed their dependence on the number of people employed in an enterprise. The data included in Table 1 indicates that the costs of an accident increase with the size of an enterprise. This is caused by the fact that in large enterprises, due to the application of more sophisticated technologies and expensive technical equipment, the costs of production disruptions and repairs are much higher.

Table 1. The average estimated cost of an accident in relation to the number of employees [11]

\begin{tabular}{|c|l|c|}
\hline No. & $\begin{array}{c}\text { Number of } \\
\text { employees }\end{array}$ & $\begin{array}{c}\text { The estimated cost of } \\
\text { an accident [PLN] }\end{array}$ \\
\hline 1 & up to 5 & 12000 \\
\hline 2 & $6-20$ & 19000 \\
\hline 3 & $21-100$ & 29000 \\
\hline 4 & $101-250$ & 49000 \\
\hline 5 & More than 250 & 63500 \\
\hline
\end{tabular}

In turn, Table 2 summarizes the costs incurred due to fatal, serious and collective accidents. It was calculated on the basis of 368 accidents that occurred in the years 2004-2009 in construction companies, healthcare, industrial processing plants and waste management plants [1].

Table 2. The costs of accidents at work [1]

\begin{tabular}{|c|c|c|c|c|}
\hline \multirow{2}{*}{$\begin{array}{c}\text { Type of } \\
\text { accident }\end{array}$} & $\begin{array}{c}\text { The average } \\
\text { total cost } \\
\text { (CAW) } \\
{[\text { [PLN] }}\end{array}$ & $\begin{array}{c}\text { The average } \\
\text { total cost of an } \\
\text { employer (CE) } \\
\text { [PLN] }\end{array}$ & $\begin{array}{c}\text { The cost of an accident } \\
\text { "cheapest-most } \\
\text { expensive" } \\
\text { (CAWmin/CAWmax) } \\
\text { [PLN] }\end{array}$ & $\begin{array}{c}\text { The average cost } \\
\text { of prevention } \\
\text { [PLN] }\end{array}$ \\
\hline fatal & 109395 & 58897 & $11685 / 344176$ & 1149 \\
\hline serious & 236904 & 213470 & $2564 / 1394456$ & 1712 \\
\hline collective & 77207 & 32435 & 143970 & 796 \\
\hline
\end{tabular}

The average cost of a fatal accident incurred by a company amounted to PLN 58,897. The average costs of serious and collective accidents amounted to PLN 213,470 and PLN 32,435 respectively. The last column gives the estimated costs of the preventive measures that should be taken to prevent an accident [1]. These costs were disproportionately low in 
relation to the total cost of an accident and ranged from $0.8 \%$ to $2.45 \%$. The included data only refers to the costs incurred in the first year after an accident. However, it should be noted that costs associated with an accident are also incurred in subsequent years and these costs are: a pension paid to an employee or a person authorized by the Department of Social Insurance and also rehabilitation costs

\section{Conclusions}

The conducted research and analysis are the basis to draw the following conclusions regarding economic losses due to accidents that occurred in Poland in 2014:

- Measurable economic losses are related to accidents at work, as well as human losses in the form of injuries of varying severity. The costs of accidents at work are incurred by a company, the victim and his family and also the whole of society.

- The consequence of accidents at work, beyond the effects causing fatal or serious body injuries, is an absence of employees. As many as $54.6 \%$ of the victims of accidents in the construction industry were qualified for sick leave lasting for more than one month. The phenomenon of absence from work caused by accidents is described by the severity rate of accidents. In 2014 the rate was equal to 52.4 workdays per one injured person. Regarding the value of this rate, the construction industry placed second in the ranking of all sections of the economy, just after mining and extraction.

- Removing the effects of accidents often requires the involvement of additional people. Based on statistical data, it can be calculated that in 2014 an average of 4 construction employees were involved in removing the effects of accidents at work throughout the whole year.

- In terms of material losses caused by accidents at work, the construction industry placed fifth in the ranking of all sections of the economy. Percentage participation of material losses in the construction industry in relation to losses incurred in all sectors of the economy amounted to $4.24 \%$.

- Analysis of accident costs has shown that the costs of an accident increase with the size of a company. This is due to the fact that large workplaces use expensive equipment and technologies, and for this reason the costs of production disruptions are bigger. The estimated hypothetical costs that should be incurred for prevention, in order to ensure occupational safety, were disproportionately low in relation to the total cost of an accident and ranged from 0.8 to $2.45 \%$.

The study is the result of the implementation by the authors of the research project No. 244388 "Model of the assessment of risk of the occurence of building catastrophes, accidents and dangerous events at workplaces with the use of scaffolding", financed by NCBiR within the framework of the Programme for Applied Research on the basis of contract No. PBS3/A2 /19/2015.

\section{References}

1. H. Purwin, „About the costs of occupational security - the costs of accidents at work", Przyjaciel przy pracy, 07, (2011)

2. B. Hoła, M. Szóstak, ACE, 61, 19-34 (2015)

3. J. Rzepecki, The social costs of accidents at work in Poland". Bezpieczeństwo Pracy, 5, (2012)

4. T.C. Haupt, K. Pillay, Journal of Engineering, Design and Technology, 14, 373-419 (2016) 
5. R. Studenski., „The organization of occupational safety in an enterprise”, Publishing House of Silesian University of Technology (1996)

6. G. M. Waehrer, Accident Analysis and Prevention, 39, 1258-1266 (2007)

7. Y. Feng, Journal of Construction Engineering and Management, 141 (2015)

8. T. E. Cressler, J. R. Moore, Safety Science, 88, 44-53 (2016)

9. www.ciop.pl (dostęp październik 2016)

10. „Accidents at work in 2014”. Central Statistical Office, Warsaw (2015)

11. E. Kowal. I. Gabryelewicz, A. Kowal, „Estimation of the costs of accidents at work in mines", 548-561 (2014) 